Takeshi Tana $\cdot$ Nobuhiro Kamikawaji

Christopher J. Savoie • Tohru Sudo • Yurika Kinoshita

Takehiko Sasazuki

\title{
An HLA-binding-motif-aided peptide epitope library: A novel library design for the screening of HLA-DR4-restricted antigenic peptides recognized by CD4 ${ }^{+} T$ cells
}

Received: October 3, 1997 / Accepted: October 23, 1997

\begin{abstract}
Susceptibility to a series of autoimmune diseases is strongly associated with particular HLA class II alleles. Identification of $\mathrm{T}$ cell clones and antigenic epitopes bound by HLA class II molecules involved in autoimmune diseases is critical to understanding the etiology of these HLA class II-associated diseases. However, establishment of T cell clones in autoimmune diseases is difficult because the antigenic peptides are unknown. Peptide library methods which include all possible peptide sequences offer a potentially powerful tool for the detection of cross-reactive antigenic peptides recognized by $\mathrm{T}$ cells. Here, we reduced the number of peptides per mixture by utilizing the known binding motifs of peptides for the HLA-DRB1*0405 molecule and evaluated the effectiveness of this library design. Each library mixture evoked a strong proliferative response in the unprimed peripheral blood lymphocytes (PBL) from $H L A$-DRB $* 0405$-positive donors but little or no response in the PBL from $H L A-D R B 1 * 0405$-negative donors. The library also detected antigenic peptides that activated three antigen-specific T cell lines restricted by HLA-DRB1*0405, with different specificities. The motif-based approach thus presents a powerful method for monitoring $\mathrm{T}$ cells in large, heterogeneous $\mathrm{T}$ cell populations and is useful for the identification of the mimic peptide epitopes of $\mathrm{T}$ cell lines and clones.
\end{abstract}

Key words Peptide library $\cdot$ Binding motif $\cdot$ HLA $\cdot H L A$ $D R B 1 * 0405 \cdot T$ cell epitope

\section{Introduction}

A great deal of progress has been made in identifying statistical associations between HLA and autoimmune diseases

T. Tana $\cdot$ N. Kamikawaji $\cdot$ C.J. Savoie $\cdot$ T. Sudo · Y. Kinoshita

T. Sasazuki $(\triangle)$

Department of Genetics, Medical Institute of Bioregulation, Kyushu

University, 3-1-1 Maidashi, Higashi-ku, Fukuoka 812, Japan

Tel. +81-92-642-6827; Fax +81-92-632-0150

e-mail: sasazuki@bioreg.kyushu-u.ac.jp
(Tiwari and Terasaki 1985; Dong et al. 1993; Yasunaga et al. 1996; Thorsby 1997). There are at least two possible mechanisms for observed associations. One is a direct involvement of HLA genes in the pathogenesis of associated diseases, and another is the effects of other genes which are in strong linkage disequilibrium with the associated HLA loci. Primary involvement of HLA molecules in HLA-associated diseases may be a result of preferential binding and presentation to potential autoreactive $\mathrm{T}$ cells of peptides derived from autoantigens, by the HLA molecule associated with the disease. As previously reported, many of these diseases are associated with HLA molecules that share particular pockets in their peptide-binding clefts, which may play a decisive role in determining which autoantigen-derived peptides may be bound (Hammer et al. 1995; Thorsby 1997). The identification of these etiologic peptides seems to be essential for investigations into immune dysfunction and autoimmune disease. Knowledge of epitopes involved in immunological disorders may facilitate therapeutic or prophylactic intervention. However, little is known about the characteristics of the autoimmune epitope peptides bound to specific HLA molecules that are associated with susceptibility to these diseases, because of the difficulty in generating $\mathrm{T}$ cell clones without knowledge of antigens.

Peptide library methods offer a potentially powerful tool for the detection of antigenic peptides recognized by $\mathrm{T}$ cells. To date, two major approaches to peptide library design using combinatorial chemistry have been successful in the identification of $\mathrm{T}$ cell antigenic peptides. One such design utilized two fixed amino acid residues of peptide at the binding anchors of an HLA class I molecule, and randomized seven other positions in a mixture. This library was used to detect mimics of tumor epitope recognized by MHC class I restricted cytotoxic T lymphocytes (CTL) (Blake et al. 1996). Another approach to peptide libraries is a "comprehensive" design in which all potential peptides of a given length are included in a peptide mixture. This approach was successfully employed in the identification of an epitope mimic recognized by a myelin basic protein (MBP)-specific, MHC class II restricted, autoreactive $\mathrm{T}$ cell clone in humans (Hemmer et al. 1997), and an alloreactive, MHC 
class I restricted T cell clone in mice (Udaka et al. 1995, 1996).

The peptide mixtures of a "comprehensive" library result in designs with more than $20^{9}$ peptide species per peptide mixture. However, the possible number of peptide species in a mixture that can be detected by $\mathrm{T}$ cells is limited by the total number of HLA molecules present in the screening system, because $\mathrm{T}$ cells respond to peptides only in the context of HLA molecules. The number of MHC molecules on an individual antigen-presenting cell has been estimated to be $10^{5}$ on average (Demotz et al. 1990; Harding and Unanue 1990; Christinck et al. 1991). The minimum number of same-species MHC/peptide complexes required for the activation of murine $\mathrm{T}$ cell clones has been estimated at $10^{2}$ complexes per cell (Demotz et al. 1990; Harding and Unanue 1990; Christinck et al. 1991). If the number of peptide species in a mixture exceeds this limit, certain of the peptide species which have relatively higher affinity to a specific MHC molecule in the mixture would bind the MHC molecule while other peptide species would remain in suspension and would be undetected, and therefore unscreened by T cells.

The HLA-DRB1*0405 molecule is one of the most frequent alleles in the Japanese population, and is associated with several autoimmune diseases including rheumatoid arthritis (Tsuchiya et al. 1992). In this report, by assigning fixed amino acid residues appropriate for the binding motif for the HLA-DRB1*0405 molecule at the four MHC anchor residues for this molecule, and by assigning fixed amino acid residues at two of six possible $\mathrm{T}$ cell receptor (TCR) contact positions, we created a combinatorial motifaided peptide epitope library (MAPEL). To evaluate the effectiveness of this design, we examined the proliferative response of peripheral blood lymphocytes (PBL) from $H L A-D R B 1 * 0405$-positive donors and HLA-DRB ${ }^{*} 0405$ negative donors, and antigen-specific $\mathrm{T}$ cell lines and $\mathrm{T}$ cell clones from $H L A-D R B 1 * 0405$-positive donors, to the MAPEL.

\section{Materials and methods}

Peptide synthesis

Peptides were synthesized on a 396MPS multiple peptide synthesizer (Advanced Chem Tech, Louisville, KY, USA), using standard F-moc amino acids with N,N'-Diisopropylcarbodiimide/1-Hydroxy-1H-benzotriazole monohydrate (DIC/HOBt) coupling chemistry on a polystyrene resin. Combinatorial peptide libraries were synthesized using a solid phase 'split synthesis' of nine peptide mixtures containing either $\mathrm{X}(\mathrm{T}, \mathrm{L}, \mathrm{K}, \mathrm{Q}, \mathrm{D}, \mathrm{M}, \mathrm{F}, \mathrm{H}, \mathrm{V})$ or $\mathrm{Z}(\mathrm{S}, \mathrm{I}, \mathrm{R}$, $\mathrm{N}, \mathrm{E}, \mathrm{C}, \mathrm{Y}, \mathrm{P}, \mathrm{W})$ group amino acids with a standard F-moc chemistry as previously reported (Lam et al. 1991; Houghten et al. 1991). After each coupling step of mixture position, the beads from each of the nine reaction vessels were combined for randomization and then split again to nine vessels for the next coupling step. After three such iterations, the $729\left(9^{3}\right)$ peptide sequences were synthesized. Peptides were cleaved from the resin with trifluoroacetic acid (TFA) containing 1\% ethanedithiol, $3 \%$ anisole, and $3 \%$ ethylmethylsulfide. The cleaved peptides were washed with diethyl ether, and frozen dry in $10 \%$ acetic acid. The quality of the cleaved peptides was monitored by reversephase HPLC (gradient from $0.1 \%$ TFA in water to $0.1 \%$ TFA in acetonitrile, UV detection at $214 \mathrm{~nm}$ ) using a C18 column (Millipore, Milford, MA, USA) and by electrospray mass spectrometry. The amino acid composition in the randomized sequence positions of the library was determined by pool sequencing. Peptides were dissolved in autoclaved double-distilled $\mathrm{H}_{2} \mathrm{O}$ at $1 \mathrm{mM}$ and stored at $-20^{\circ} \mathrm{C}$. The amino acid residues are usually referred to by the one-letter amino acid code, and sometimes by the full-letter code.

\section{HLA DNA typing}

DNA was extracted from the peripheral granulocytes of each subject following the protocol of the 11th International Histocompatibility Workshop (Kimura and Sasazuki 1992). HLA class II genes (DRB1, DRB3, DRB4, DRB5, DQA1, $D Q B 1, D P A 1, D P B 1)$ were determined by polymerase chain reaction/oligonucleotide probes (PCR/SSOP) analysis, as described previously (Kimura et al. 1992).

\section{Generation of $\mathrm{T}$ cell lines}

A purified protein derivative (PPD)-specific T cell line was generated as previously reported (Dong et al. 1995) from a healthy donor, TT $(D R B 1 * 0405 / 0802, D Q A 1 * 0302 / 0401$, $\left.D Q B 1 * 0401 / 0402, \quad D P A 1^{*} 01 / 02021, \quad D P B 1 * 1901 /-\right) . \quad$ A streptococcal cell wall antigen (SCW)-specific $\mathrm{T}$ cell line was generated as a PPD-specific T cell line from another healthy donor, TS $(D R B 1 * 0405 / 0901, D Q A 1 * 0301 /$, $D Q B 1 * 0401 / 0303, \quad D P A 1 * 02022 /-, \quad D P B 1 * 0501 /-)$. An HLA-DRB1*08032-specific T cell line was generated from PBL of an HLA-DRB1*0405 homozygous donor, HK (DRB1*0405/-, DQA1*0302/-, DQB1*0401/-, DPA1*02022/-, $D P B 1 * 0501 /-$ ), by stimulating with irradiated (30 Gy) PBL from an $H L A-D R B 1 * 08032$ heterozygous donor, KK (DRB1*0405/08032, DQA1*0302/0103, DQB1*0401/06012, $D P A 1 * 02022 / 0103, D P B 1 * 0501 / 0201)$.

\section{Transfectant}

HLA class II DR4 $(D R A * 0102 / D R B 1 * 0405) \alpha$ and $\beta$ genes were cotransfected with PAG60 harboring a neomycinresistant gene into a mouse $\mathrm{L}$ fibroblast cell line as described previously (L-DR4) (Kamikawaji et al. 1991).

\section{$\mathrm{T}$ cell proliferation assay}

PBL were separated by using a density gradient centrifugation method. PBL $\left(1 \times 10^{5}\right)$ were cultured in each well of a round-bottomed 96-well microtiter plate (Corning, NY, USA) in $200 \mu \mathrm{l}$ RPMI 1640 medium(Life Technologies, 
Grand Island, NY, USA) supplemented with $10 \%$ pooled male human serum (HS), $2 \mathrm{mM}$ L-glutamine (Life Technologies), and $100 \mathrm{U} / \mathrm{ml}$ penicillin- $100 \mu \mathrm{g} / \mathrm{ml}$ streptomycin (Life Technologies), with $50 \mu \mathrm{M}$ HLA-DRB1*0405 MAPEL. Cells were cultured at $37^{\circ} \mathrm{C}$ with $5 \% \mathrm{CO}_{2}$ in a humidified atmosphere for 6 days and pulsed with $1 \mu \mathrm{Ci}$ of ${ }^{3} \mathrm{H}$-thymidine (ICN Biomedicals, Casta Mesa, CA, USA). Cells were harvested on glass fiber filters (Wallac, Turku, finland) after an additional 18-h culture, and incorporated radioactivity was measured by a liquid scintillation counter (Wallac). Results were expressed as the mean counts per minute (cpm) of five well cultures.

Antigen-specific proliferation of the $\mathrm{T}$ cell line was assayed by culturing the cells $\left(4 \times 10^{4} /\right.$ well $)$ in 96 -well flatbottom culture plates in the presence or absence of synthetic peptide using mitomycin C treated L-DR4 (3.5 $\times$ $10^{4} /$ well) in a total volume of $200 \mu \mathrm{l}$, as described (Kamikawaji et al. 1991). Cells were cultured for $72 \mathrm{~h}$ in the presence of $1 \mu \mathrm{Ci} /$ well of ${ }^{3} \mathrm{H}$-thymidine for the last $12 \mathrm{~h}$. Cells were harvested on glass fiber filters (Wallac, Turku, finland), and the incorporated radioactivity was measured by a liquid scintillation counter (Wallac). Results were expressed as the mean cpm of duplicate cultures.

\section{Results}

Design strategy for the HLA-DRB1*0405 motif-aided peptide epitope library

A binding motif for HLA-DRB $1 * 0405$-associated peptides has been elucidated by several investigators from analysis of endogenous peptides eluted from the molecule (Kinouchi et al. 1994; Matsushita et al. 1994; Rammensee et al. 1995; Friede et al. 1996). The motif is composed of nine amino acid residues of which position $1,4,6$, and 9 (P1, P4, P6, and $\mathrm{P} 9)$ are considered to be anchor positions as shown in Table 1. We have identified three antigenic peptides presented by the HLA-DRB1*0405 molecule. These peptides were derived from streptococcal M12 protein, Cryptomeria japonica pollen antigen 1 (Cry j 1), or Cryptomeria japonica pollen antigen 2 (Cry j 2) (Table 2). M12 peptide 347-367 was previously reported to be an antigenic peptide recognized by M12-specific and HLADRB1*0405-restricted T cell lines (Dong et al. 1995). According to alanine substitution analysis and truncated peptide analysis, a nine amino acid peptide, M12 355-363, was demonstrated to be the core antigenic peptide recognized by the $\mathrm{T}$ cell line. This peptide fits the binding motif
Table 1 HLA-DRB1*0405 binding motif: eluted peptide information

\begin{tabular}{|c|c|c|c|c|c|c|c|c|c|}
\hline P0 & P1 & $\mathrm{P} 2$ & P3 & P4 & P5 & P6 & P7 & P8 & P9 \\
\hline & FY & & & VI & & NS & & & DE \\
\hline & WV & & & LM & & TQ & & & $\mathbf{Q}$ \\
\hline & $\begin{array}{l}\text { IL } \\
\mathbf{M}\end{array}$ & & & DE & & KD & & & \\
\hline
\end{tabular}

Data from Rammensee et al. 1995.

Bold represents putative anchor points.

for HLA-DRB1*0405 at P1 leucine, P4 leucine, and P9 aspartic acid. Within the 20 mer peptide of Cry j 1 (Hori et al. 1996), which was recognized by a Cry $\mathrm{j} 1$-specific, HLA-DRB1*0405-restricted T cell line, Cry j 1 235-254 fit the binding motif at $\mathrm{P} 1$ valine, $\mathrm{P} 6$ asparagine, and P9 aspartic acid. Similarly, within the 20 mer peptide of Cry j 2 (Hori et al. 1996), which was recognized by a Cry $\mathrm{j} 2$ specific, HLA-DRB1*0405-restricted T cell line, Cry j 2 145-164 fit the binding motif at P1 phenylalanine, P4 valine, and $\mathrm{P} 9$ glutamic acid. It was reported that substitutions among residues permissive for HLA binding at the HLA anchor sites have relatively little effect on T cell activity compared with alterations at TCR contact residues (Suhrbier et al. 1991; Reay et al. 1994; Kuchroo et al. 1994). Thus, we assigned a single, fixed, binding-permissive residue at each of these anchor residue positions, P1Y, P4L, P6A, and P9D.

The remaining positions, $\mathrm{P} 2, \mathrm{P} 3, \mathrm{P} 5, \mathrm{P} 7$, and $\mathrm{P} 8$, were considered to be putative TCR contact positions. In addition, the amino acid at $\mathrm{P} 0$ (on the $\mathrm{N}$ terminal side of the first anchor residue P1) was previously suggested to be a critical residue in the activation of myelin basic protein (MBP)specific $\mathrm{T}$ cell clones (Wucherpfennig et al. 1995; Wucherpfennig and Strominger 1995). Including this position (P0), we assigned six positions as putative TCR contact sites (P0, P2, P3, P5, P7, and P8). Among the putative TCR contact residues, not all residues are simultaneously critical for recognition by cloned T cells, and substitution by certain other amino acids at noncritical positions also has relatively little adverse effect on T cell activity (Kuchroo et al. 1994; Evavold et al. 1992; Kersh and Allen 1996). We assigned a fixed, unobtrusive amino acid alanine to two of these six positions, and randomized the remaining four positions, giving 15 combinations of 4 -site randomizations $(6 \mathrm{C} 4=15)$ for putative TCR contact residues. We divided 18 amino acids into two groups, $\mathrm{X}(\mathrm{T}, \mathrm{L}, \mathrm{K}, \mathrm{Q}, \mathrm{D}, \mathrm{M}, \mathrm{F}, \mathrm{H}, \mathrm{V})$ and $\mathrm{Z}$ $(\mathrm{S}, \mathrm{I}, \mathrm{R}, \mathrm{N}, \mathrm{E}, \mathrm{C}, \mathrm{Y}, \mathrm{P}, \mathrm{W})$, and placed either $\mathrm{X}$ or $\mathrm{Z}$ at each of the four putative TCR contact positions. Thus, we developed 15 sets of heterogeneous peptide mixtures grouped according to the nine different amino acids of either the $\mathrm{X}$ or $\mathrm{Z}$ group at the putative $\mathrm{T}$ cell contact residue closest to

Table 2 Antigenic peptides recognized by three T cell lines from $H L A$-DRB $* 0405$-positive donors

\begin{tabular}{|c|c|c|c|c|c|c|c|c|c|c|c|c|}
\hline Cell line & & $\mathrm{P} 0$ & P1 & $\mathrm{P} 2$ & P3 & $\mathbf{P 4}$ & P5 & P6 & $\mathrm{P} 7$ & $\mathrm{P} 8$ & P9 & \\
\hline (M12 protein $355-367)$ & & & $\mathbf{L}$ & A & $\mathrm{N}$ & $\mathbf{L}$ & $\mathrm{T}$ & $\mathbf{A}$ & $\mathrm{E}$ & $\mathrm{L}$ & D & \\
\hline (Cry j 1 235-254) & YG & $\mathrm{L}$ & $\mathbf{V}$ & $\mathrm{H}$ & $\mathrm{V}$ & $\mathbf{A}$ & $\mathrm{N}$ & $\mathbf{N}$ & $\mathrm{N}$ & $\mathrm{Y}$ & $\mathbf{D}$ & PWTIYAIG \\
\hline (Cry j 2 145-164) & LKLMNSP & $\mathrm{E}$ & $\mathbf{F}$ & $\mathrm{H}$ & $\mathrm{L}$ & $\mathbf{V}$ & $\mathrm{F}$ & G & $\mathrm{N}$ & $\mathrm{C}$ & $\mathbf{E}$ & GVK \\
\hline
\end{tabular}

Bold represents putative anchor points. 
the $\mathrm{N}$ terminal end ( $\mathrm{P} 0, \mathrm{P} 2$, or $\mathrm{P} 3)$, with the other three putative $\mathrm{T}$ cell contact positions randomized among the nine $\mathrm{X}$ or $\mathrm{Z}$ group amino acids. $\mathrm{N}$-terminal $\mathrm{K}, \mathrm{E}$ and $\mathrm{C}$-terminal $\mathrm{A}, \mathrm{E}, \mathrm{K}$ were added to all peptides to increase solubility and to stabilize the MHC/ peptide/ TCR interactions (Fig. 1).

PBL proliferation induced by the HLA-DRB1*0405 MAPEL

We examined the proliferative responses of unstimulated PBL to the MAPEL peptide mixtures. PBL from an $H L A$ $D R B 1 * 0405$ homozygote were cultured with each of 135 heterogeneous peptide mixtures of the HLA-DRB1*0405 MAPEL for 1 week and the proliferative responses were measured by ${ }^{3} \mathrm{H}$-thymidine uptake assays. In fig. 1, 135 peptide mixtures of the HLA-DRB1*0405 MAPEL are shown; of these, $19 \%$ (25 mixtures) induced strong proliferation of PBL (>45,000 cpm), 43\% (58 mixtures) induced moderate proliferation $(>15,000 \mathrm{cpm},<45,000 \mathrm{cpm})$, and $38 \%(52$ mixtures) induced weak proliferation $(<15,000 \mathrm{cpm})$. Thus, all peptide mixtures had the ability to induce some $\mathrm{T}$ cell proliferation without prior immunization. Furthermore, blocking experiments using anti-HLA-DR monoclonal antibodies (mAbs;HU-4) confirmed that this proliferation was HLA-DRBI*0405 restricted (data not shown).

Fig. 1 Activation of unprimed peripheral blood lymphocytes (PBL) from an $H L A$ -

$D R B 1 * 0405$ homozygote by the HLA-DRB $1 * 0405$ motif-aided peptide epitope library (MAPEL). PBL from an $H L A$ $D R B 1 * 0405$ homozygote were cultured with each of the 135 heterogeneous peptide mixtures of the HLA-DRB $1 * 0405$ MAPEL for 1 week and the proliferative responses were measured by ${ }^{3} \mathrm{H}$-thymidine uptake assays. Results are expressed as the mean cpm of five well cultures. The SE is indicated by error bars. The final concentration of each peptide mixture was $50 \mu \mathrm{M}$. The response without peptide mixtures was less than $1000 \mathrm{cpm}$
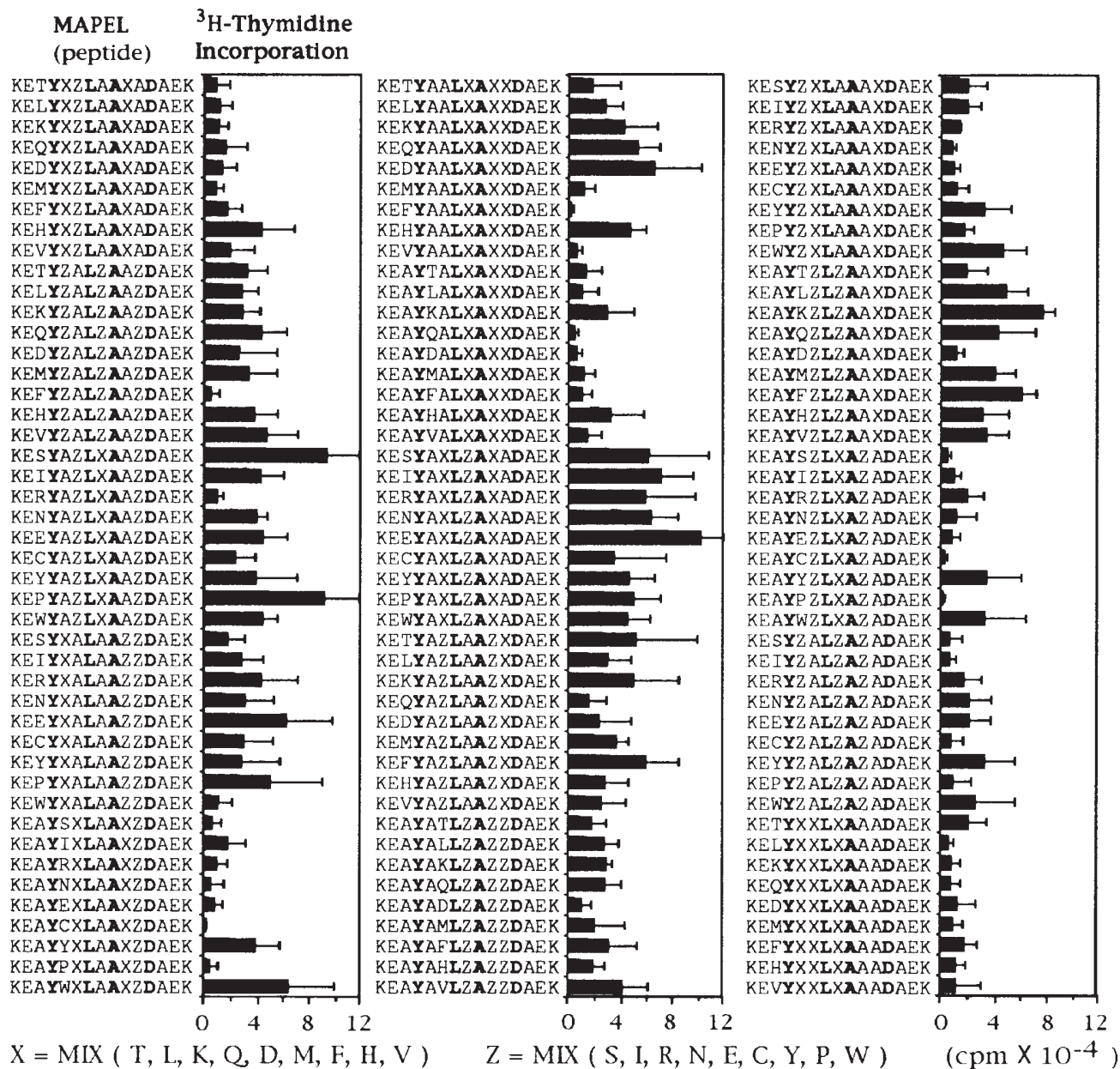

$\mathrm{X}=\operatorname{MIX}(\mathrm{T}, \mathrm{L}, \mathrm{K}, \mathrm{Q}, \mathrm{D}, \mathrm{M}, \mathrm{F}, \mathrm{H}, \mathrm{V})$
We further studied the proliferative responses of unstimulated PBL from six healthy adults (three $H L A$ $D R B 1 * 0405$-positive donors, three $H L A-D R B 1 * 0405$ negative donors) to 63 mixtures (Fig. 2). Over half of the 63 peptide mixtures induced moderate or strong proliferation (>15,000 cpm) of PBL from HLA-DRB1*0405-positive donors. In contrast, most of the 63 peptide mixtures induced only weak proliferation $(<15,000 \mathrm{cpm})$ of PBL from $H L A$ $D R B 1 * 0405$-negative donors, indicating that the library was indeed optimized for the binding motif of HLADRB1*0405. In addition, there were close correlations in the proliferative response patterns to the MAPEL among the three $H L A-D R B 1 * 0405$ heterozygotes. The correlation coefficients between individuals were 0.73 between NK and HA, 0.71 between NK and SN, and 0.62 between HA and SN. These correlations were well over 0.32 , the criterion for statistical significance of $1 \%$. The proliferation of PBL in seven additional $H L A-D R B 1 * 0405$-positive donors was further examined. The average of the correlation coefficients among 10 donors was 0.53 (data not shown). Thus, the HLA-DRB1*0405 MAPEL can induce proliferation of PBL from $H L A-D R B 1 * 0405$-positive adult donors more effectively and specifically than in PBL from $H L A$ $D R B 1 * 0405$-negative adult donors, and PBL from $H L A$ $D R B 1 * 0405$-positive adult donors have highly similar response characteristics to the peptide mixtures of the 


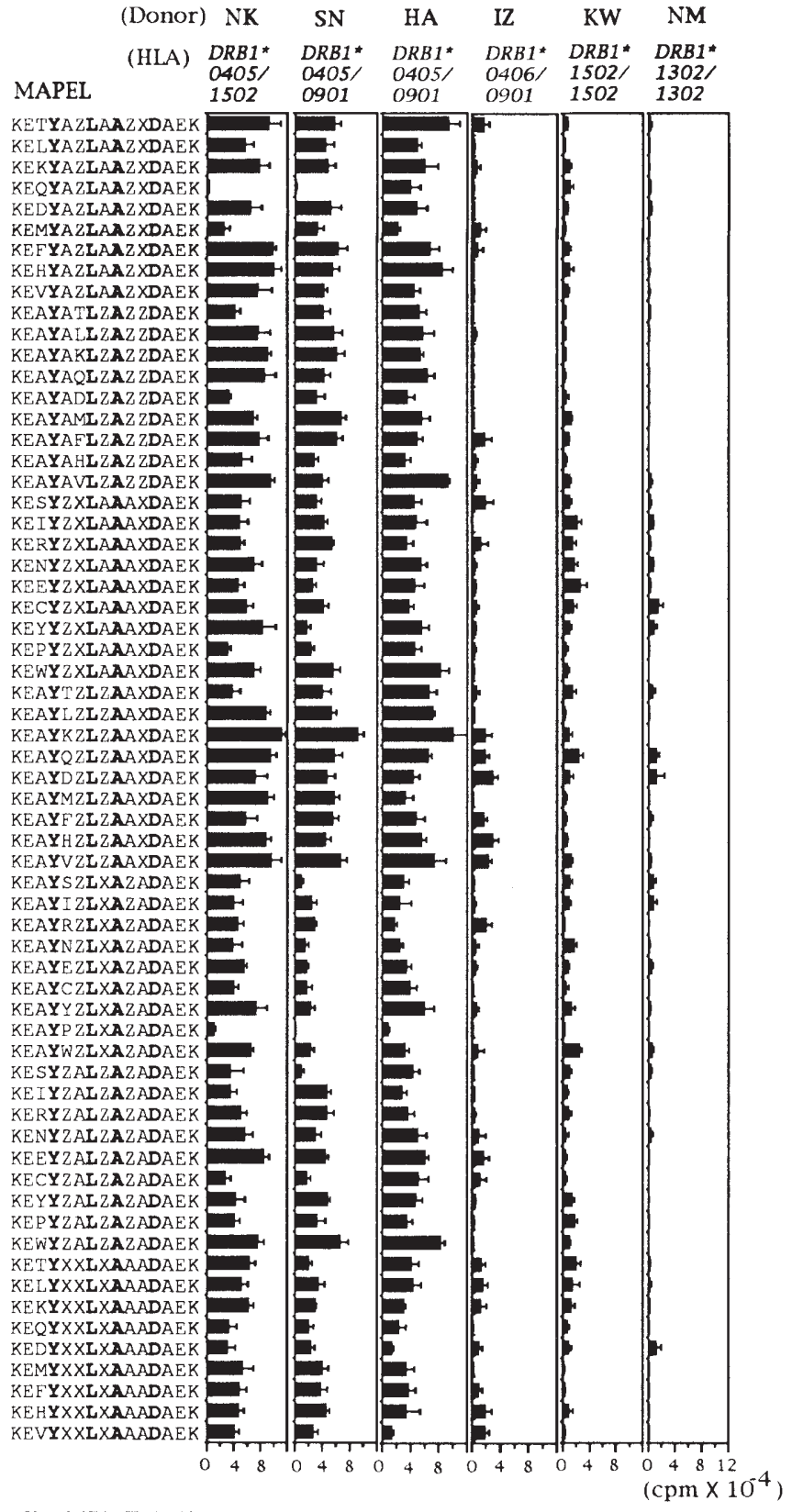

$X=\operatorname{MLX}(T, L, K, Q D, M, F, H, V), Z=\operatorname{MIX}(S, I, R, N, E, C, Y, P, W)$

Fig. 2 Proliferative responses of PBL from six adults to 63 mixtures of the HLA-DRB1*0405 MAPEL. The method was in accordance with fig. 1. The HLA type of each donor is shown at the top of the figure; there were three $H L A-D R B 1 * 0405$-positive donors and three $H L A$ $D R B 1 * 0405$-negative donors. Results are expressed as the mean cpm of five well cultures. The SE is indicated by error bars

HLA-DRB $1 * 0405$ MAPEL. This indicated that each peptide mixture of the MAPEL could induce proliferation of $\mathrm{T}$ cell repertoires generally in $H L A-D R B 1 * 0405$-positive donors without immunization, and that the observed responses were not influenced by another $H L A-D R B 1$ allele.

Influence of the HLA-binding motif on PBL proliferation

We further investigated the influence of the HLA-binding motif on PBL proliferation against library mixtures using
HLA-DRB1*0101-motif-oriented peptide mixtures and HLA-DRB1*0901-motif-oriented peptide mixtures, both of which were composed of nine sets of peptide mixtures. In these mixtures, we assigned a single, fixed, binding-permissive residue at each of the anchor residue positions, P1Y, P4L, P6A, and P9L for HLA-DRB1*0101-motif-oriented peptide mixtures, and P1Y, P4 S, P6A, and P9A for HLADRB1*0901-motif-oriented peptide mixtures, based on information from eluted peptides from HLA-DRB1*0101 and HLA-DRB1*0901 (Rammensee et al. 1995; Futaki et al. 1995). At the TCR contact sites, the sequence combinations which induced the strongest PBL proliferation by $H L A-D R B 1 * 0405$-positive donors in the case of HLADRB1*0405 MAPEL were used. In the HLA-DRB1*0101motif-oriented peptide mixtures, only the P9 position was different from the corresponding HLA-DRB $1 * 0405$ mixture. For the HLA-DRB1*0901-motif-oriented peptide mixtures, $\mathrm{P} 4$ and $\mathrm{P} 9$ position residues were different from those with HLA-DRB1*0405-oriented motifs.

We examined the proliferation of PBL in an $H L A$ $D R B 1 * 0405$ homozygote and an HLA-DRB1*0101 homozygote to the nine sets of peptide mixtures for both alleles (Fig. 3a). The peptide mixtures of HLA-DRB $1 * 0405$ MAPEL induced an average of $28,000 \mathrm{cpm}$ proliferation of PBL from an $H L A-D R B 1^{*} 0405$-positive donor, but only an average of $8000 \mathrm{cpm}$ proliferation of PBL from an $H L A$ $D R B 1 * 0101$-positive donor. Conversely, the HLADRB1*0101-motif-oriented peptide mixtures induced an average of 20,000 cpm proliferation of PBL from an $H L A$ $D R B 1 * 0101$-positive donor, and only $5000 \mathrm{cpm}$ average proliferation of PBL from an $H L A-D R B 1^{*} 0405$-positive donor. Thus, even a difference in one residue on the peptide between two HLA-DR allelic products was sufficient to cause drastic differences in PBL responses.

We also examined the proliferation of PBL from two $H L A-D R B 1 * 0405$-positive donors and two HLA$D R B 1 * 0901$-positive donors to the nine sets of peptide mixtures for both alleles (Fig. 3b). The peptide mixtures of HLA-DRB $1 * 0405$ MAPEL induced an average of $27,000 \mathrm{cpm}$ proliferation of PBL from two $H L A$ $D R B 1 * 0405$-positive donors, but only an average of $4000 \mathrm{cpm}$ in PBL from two $H L A-D R B 1 * 0901$-positive donors. Conversely, the HLA-DRB1*0901-motif-oriented peptide mixtures induced an average of $38,000 \mathrm{cpm}$ proliferation of PBL from two $H L A-D R B 1^{*} 0901$-positive donors, and an average of $8000 \mathrm{cpm}$ in PBL from two HLA$D R B 1 * 0405$-positive donors. These results indicated that each HLA-binding anchor (HLA natural ligand motif) plays a potentially important role in the formation of the antigenic repertoires recognized by adult peripheral $\mathrm{T}$ cells, and that the binding motif is indeed an important factor for proliferative sensitivity in the MAPEL design.

The detection of $\mathrm{T}$ cell epitopes of specific $\mathrm{T}$ cell lines by using the HLA-DRB1*0405 MAPEL

We examined the proliferative responses to the HLADRB1*0405 MAPEL by seven T cell lines and seven T cell 


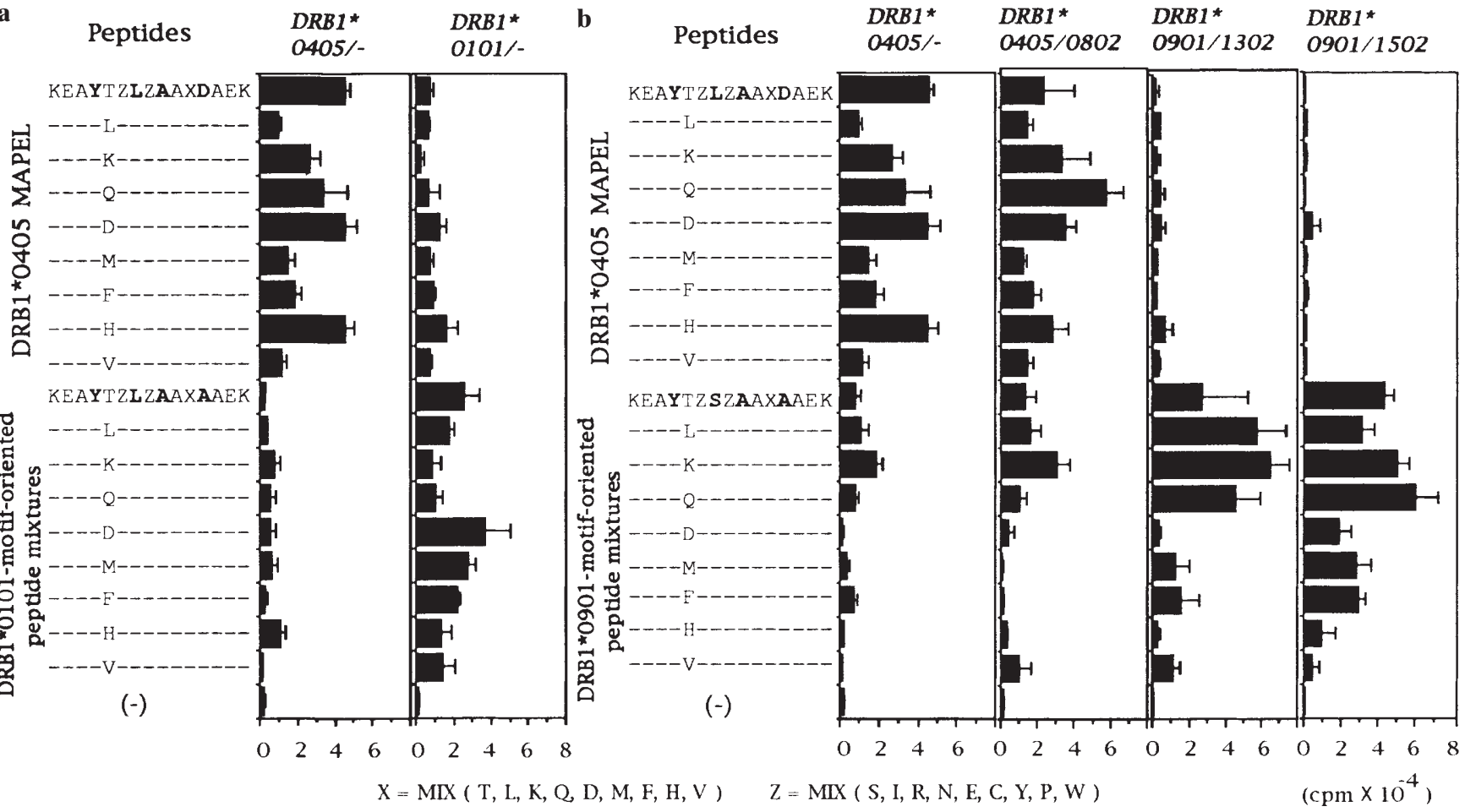

Fig. 3 Proliferative responses of PBL from adults to the nine sets of the HLA-DRB1*0405 MAPEL and the nine sets of both the HLADRB1*0101-motif-oriented peptide mixtures and HLA-DRB1*0901-motif-oriented peptide mixtures. The methods were the same as in fig. 1 . The HLA type of each donor is shown at the top of the figure. a Proliferation of PBL from an $H L A-D R B 1^{*} 0405$ homozygote and an $H L A$ $D R B 1 * 0101$ homozygote in response to the nine sets of both the HLA-DRB1*0405 MAPEL and the HLA-DRB1*0101-motif-oriented peptide mixtures. b Proliferation of PBL from two $H L A$-DRB1*0405-positive donors and two $H L A-D R B 1 * 0901$-positive donors in response to both the HLA-DRB1*0405 MAPEL and the HLA-DRB1*0901-motif-oriented peptide mixtures. Results are expressed as the mean cpm of five well cultures. The SE is indicated by error bars

Fig. 4 The detection of T cell epitope of specific T cell lines by using the HLA-DRB1*0405 MAPEL. The MAPEL was screened for the ability of individual peptide mixtures to activate an HLA-DRB1*08032specific $\mathrm{T}$ cell line (alloreactive $\mathrm{T}$ cells), a purified protein derivative (PPD)-specific T cell line, and a streptococcal cell wall antigen (SCW)-specific $\mathrm{T}$ cell line, all derived from $H L A-D R B 1 * 0405$-positive donors. After a 3-week culture with each antigen, each resulting $\mathrm{T}$ cell line was cultured with the HLA-DRB1*0405 MAPEL with L-DR4 as antigen-presenting cells for three days. Proliferative responses were measured by ${ }^{3} \mathrm{H}$-thymidine uptake assays. Results are expressed as the mean cpm of duplicate cultures. The SE is indicated by error bars. The final concentration of each peptide mixture was $50 \mu \mathrm{M}$ The response without peptide mixtures was less than $500 \mathrm{cpm}$

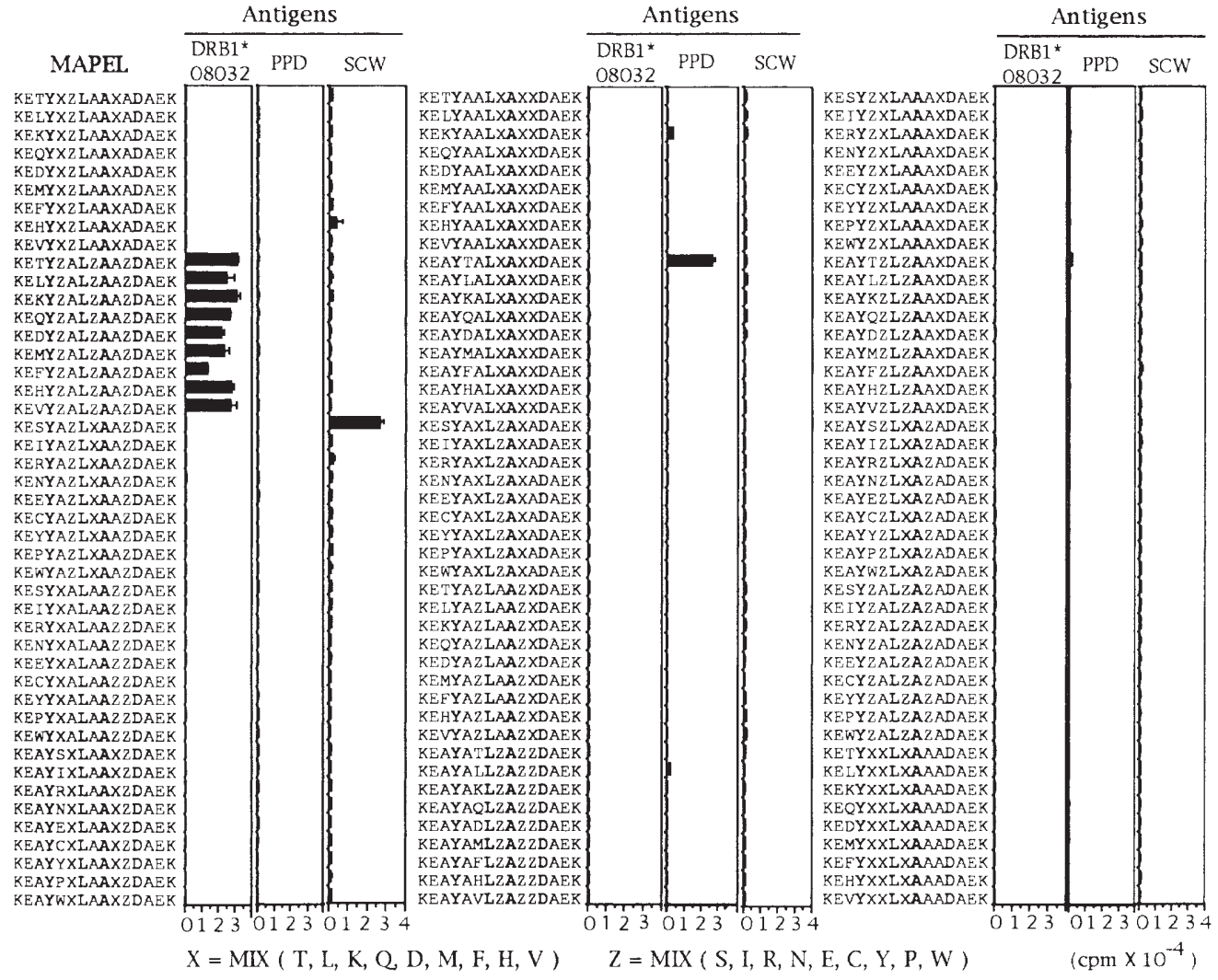


clones (two alloreactive $\mathrm{T}$ cell lines and six $\mathrm{T}$ cell clones specific to HLA-DRB1*08032, one PPD-specific T cell line and clone, $4 \mathrm{SCW}$-specific $\mathrm{T}$ cell lines), all derived from $H L A$-DRB ${ }^{*} 0405$-positive donors. The aim was to evaluate the ability of the MAPEL to resolve different epitope specificities by measuring the $\mathrm{T}$ cell proliferative response using L-DR4 as the antigen-presenting cell. Among these 14, four $\mathrm{T}$ cell lines and three $\mathrm{T}$ cell clones responded to at least one peptide mixture within the HLA-DRB1*0405 MAPEL (data not shown). Figure 4 shows three typical cases of $\mathrm{T}$ cell line responses to the HLA-DRB1*0405 MAPEL. Nine of the 135 peptide mixtures induced strong proliferation, more than $15,000 \mathrm{cpm}$, of the HLA-DRB1*08032-specific and alloreactive $\mathrm{T}$ cell line from an $H L A-D R B 1 * 0405$ homozygote; the background response was $500 \mathrm{cpm}$.

In contrast to this alloreactive $\mathrm{T}$ cell line, only one mixture from the MAPEL induced strong proliferation of the PPD-specific $\mathrm{T}$ cell line from an $H L A-D R B 1 * 0405$ heterozygote, and another mixture from the MAPEL induced strong proliferation of the SCW-specific T cell line (Fig. 4). Although almost all peptide mixtures induced the proliferation of PBL from $H L A-D R B 1 * 0405$-positive donors, only 1-9 mixtures induced the proliferation of each $T$ cell line. This indicated that each residue of the peptide mixture was indeed important in distinguishing the activity of specific $\mathrm{T}$ cells in heterogeneous $\mathrm{T}$ cell populations.

\section{Discussion}

The present design of the peptide library utilized a subset of peptides that fit the binding motif for the target HLA molecule. The peptides were further divided into separate mixtures by assigning fixed, relatively unobtrusive amino acid residues (alanine, in this case) to two of the six putative TCR contact points and alternating these fixed positions in different mixtures to generate the library. The primary advantage of this design is that most peptides in the mixture are actually screened by T cells, as compared with "comprehensive" design, due to smaller numbers of peptide species in comparable mixtures. The strong and specific responses of $\mathrm{T}$ cell lines and clones of different antigenic specificities to separate mixtures in the present library indicated the successful separation of different antigenic repertoires by the present design (Fig. 4). This feature makes it possible to resolve the TCR specificity of T cell subpopulations within heterogeneous $\mathrm{T}$ cell populations such as PBL, or autoreactive $\mathrm{T}$ cells localized at the pathological sites of autoimmune diseases.

It can be estimated that at least one cell in $10^{5} \mathrm{PBL}$ was capable of cross-reacting with at least one individual peptide of the 729 peptide species of the mixture since $10^{5}$ unprimed PBL in a microtiter well were able to respond to each combination of the 729 peptide species (Fig. 1). This suggests a high level of antigenic promiscuity for T cells in PBL. Only PBL from HLA-DRB1*0405-positive donors responded to the HLA-DRB1*0405 library, indicating that the PBL responses to library mixtures were due to optimi- zation for the HLA-DRB1*0405-binding motif (Fig. 2). Furthermore, peptide mixtures designed in consideration of the binding motifs for HLA-DRB $1 * 0101$ and HLADRB1*0901 showed reactivity only to PBL from donors with the respective alleles, suggesting that the association of certain autoimmune diseases with specific HLA genes may be related to the peptide motif of the HLA molecule. Thus, by limiting the peptides in the library to those which possess the binding motif for a given HLA molecule, it is possible to optimize a peptide library for the detection of epitopes that are predominant in the PBL of donors with a given HLA allele. This could be primarily due to the preferentially high binding affinities of library peptides to the targeted HLA molecule. Such specific analysis of the effects of the HLA-binding motif on $\mathrm{T}$ cell proliferation defines more accurately the peptide motif, and thus is useful for databaseoriented epitope prediction.

The current MAPEL design exhibits increased sensitivity and separation, compared with comprehensive designs, allowing for the direct screening of unprimed $\mathrm{T}$ cell proliferative responses in adult $\mathrm{PBL}$, in addition to the detection of epitopes for $\mathrm{T}$ cell lines and clones. However, reductions in the total number of tested peptides per mixture may reduce the comprehensiveness of the library. A truly optimized design would offer the maximized balance between resolution and sensitivity. Although any design utilizing mixtures of peptides to screen iteratively $\mathrm{T}$ cell activity is inherently biased toward the selection of highly promiscuous or cross-reactive $\mathrm{T}$ cell clones, for the investigation of $\mathrm{T}$ cell epitopes involved in autoimmune diseases (Barnaba and Sinigaglia1997) and graft-versus-host disease, where T cell cross-reaction and TCR promiscuity have been implicated as mechanisms of disease pathogenesis and causation, some bias towards cross-reactive clones may not adversely affect the usefulness of library approaches for the identification of $\mathrm{T}$ cell antigen specificities.

The major problem in the search for pathogenic autoimmunogens is the difficulty in obtaining autoreactive $\mathrm{T}$ cell clones from patients. While library methods can only identify "mimics" of actual antigenic peptides, these mimics can be used to culture $T$ cells involved in disease and search for the actual target autoantigen of these $\mathrm{T}$ cells.

Acknowledgments This work was supported in part by grants from the Ministry of Education, Science, Sports and Culture, from the Science and Technology Agency, and from the Ministry of Health and Welfare, Japan.

\section{References}

Barnaba V, Sinigaglia F (1997) Molecular mimicry and T cell-mediated autoimmune disease. J Exp Med 185:1529-1531

Blake J, Johnston JV, Hellstrom KE, Marquardt H, Chen L (1996) Use of combinatorial peptide libraries to construct functional mimics of tumor epitopes recognized by MHC class I-restricted cytolytic T lymphocytes. J Exp Med 184:121-130

Christinck ER, Luscher MA, Barber BH, Williams DB (1991) Peptide binding to class I MHC on living cells and quantitation of complexes required for CTL lysis. Nature 352:67-70

Demotz S, Grey HM, Sette A (1990) The minimal number of class II 
MHC-antigen complexes needed for T cell activation. Science 249: 1028-1030

Dong RP, Kimura A, Hashimoto H, Akizuki M, Nishimura Y, Sasazuki T (1993) Difference in HLA-linked genetic background between mixed connective tissue disease and systemic lupus erythematosus. Tissue Antigens 41:20-25

Dong RP, Kamikawaji N, Toida N, Fujita Y, Kimura A, Sasazuki T (1995) Characterization of T cell epitopes restricted by HLA-DP9 in streptococcal M12 protein. J Immunol 154:4536-4545

Evavold BD, Williams SG, Hsu BL, Buus S, Allen PM (1992) Complete dissection of the $\mathrm{Hb}(64-76)$ determinant using $\mathrm{T}$ helper $1, \mathrm{~T}$ helper 2 clones, and T cell hybridomas. J Immunol 148:347-353

Friede T, Gnau V, Jung G, Keilholz W, Stevanovic S, Rammensee HG (1996) Natural ligand motifs of closely related HLA-DR4 molecules predict features of rheumatoid arthritis-associated peptides. Biochim Biophys Acta 1316:85-101

Futaki G, Kobayashi H, Sato K, Taneichi M, Katagiri M (1995) Naturally processed HLA-DR9/DR53 (DRB1*0901/DRB4*0101)-bound peptides. Immunogenetics 42:299-301

Hammer J, Gallazzi F, Bono E, Karr RW, Guenot J, Valsasnini P, Nagy ZA, Sinigaglia F (1995) Peptide binding specificity of HLADR4 molecules: correlation with rheumatoid arthritis association. J Exp Med 181:1847-1855

Harding CV, Unanue ER (1990) Quantitation of antigen-presenting cell MHC class II/peptide complexes necessary for T-cell stimulation. Nature 346:574-576

Hemmer B, Fleckenstein BT, Vergelli M, Jung G, McFarland H, Martin R, Wiesmuller KH (1997) Identification of high potency microbial and self ligands for a human autoreactive class II-restricted T cell clone. J Exp Med 185:1651-1659

Hori T, Kamikawaji N, Kimura A, Sone T, Komiyama N, Komiyama S, Sasazuki T (1996) Japanese cedar pollinosis and HLA-DP5. Tissue Antigens 47:485-491

Houghten RA, Pinilla C, Blondelle SE, Appel JR, Dooley CT, Cuervo JH (1991) Generation and use of synthetic peptide combinatorial libraries for basic research and drug discovery. Nature 354:84-86

Kamikawaji N, Fujisawa K, Yoshizumi H, Fukunaga M, Yasunami M, Kimura A, Nishimura Y, Sasazuki T (1991) HLA-DQ-restricted CD4+ T cells specific to streptococcal antigen present in low but not in high responders. J Immunol 146:2560-2567

Kersh GJ, Allen PM (1996) Structural basis for T cell recognition of altered peptide ligands: a single $\mathrm{T}$ cell receptor can productively recognize a large continuum of related ligands. J Exp Med 184:12591268

Kimura A, Sasazuki T (1992) Eleventh International Histocompatibility Workshop reference protocol for the HLA DNA-typing technique. In: Tsuji K, Aizawa M, Sasazuki T (eds) HLA 1991, vol 1. Oxford University Press, New York, pp 397-419

Kimura A, Dong RP, Harada H, Sasazuki T (1992) DNA typing of HLA class II genes in B-lymphoblastoid cell lines homozygous for HLA. Tissue Antigens 40:5-12
Kinouchi R, Kobayasi H, Sato K, Kimura S, Katagiri M (1994) Peptide motifs of HLA-DR4/DR53 (DRB1*0405/DRB4*0101) molecules. Immunogenetics 40:376-378

Kuchroo VK, Greer JM, Kaul D, Ishioka G, Franco A, Sette A, Sobel RA, Lees MB (1994) A single TCR antagonist peptide inhibits experimental allergic encephalomyelitis mediated by a diverse $\mathrm{T}$ cell repertoire. J Immunol 153:3326-3336

Lam KS, Salmon SE, Hersh EM, Hruby VJ, Kazmierski WM, Knapp RJ (1991) A new type of synthetic peptide library for identifying ligand-binding activity. Nature 354:82-84

Matsushita S, Takahashi K, Motoki M, Komoriya K, Ikagawa S, Nishimura Y (1994) Allele specificity of structural requirement for peptides bound to HLA -DRB1*0405 and -DRB1*0406 complexes: implication for the HLA-associated susceptibility to methimazoleinduced insulin autoimmune syndrome. J Exp Med 180:873-883

Rammensee HG, Friede T, Stevanoviic S (1995) MHC ligands and peptide motifs: first listing. Immunogenetics 41:178-228

Reay PA, Kantor RM, Davis MM (1994) Use of global amino acid replacements to define the requirements for MHC binding and T cell recognition of moth cytochrome $c$ (93-103). J Immunol 152:39463957

Suhrbier A, Rodda SJ, Ho PC, Csurhes P, Dunckley H, Saul A, Geysen HM, Rzepczyk CM (1991) Role of single amino acids in the recognition of a T cell epitope. J Immunol 147:2507-2513

Thorsby E (1997) Invited anniversary review: HLA-associated diseases. Hum Immunol 53:1-11

Tiwari JL, Terasaki PI (1985) HLA and disease association. SpringerVerlag, New York

Tsuchiya K, Kondo M, Kimura A, Nishimura Y, Sasazuki T(1992) The HLA-DRB1 and/or the DQB1 locus controls susceptibility and the DRB1 locus controls resistance to rheumatoid arthritis in the Japanese. In: Tsuji K, Aizawa M, Sasazuki T (eds) HLA 1991, vol 2. Oxford University Press, New York, pp 509-512

Udaka K, Wiesmuller KH, Kienle S, Jung G, Walden P (1995) Decrypting the structure of major histocompatibility complex class Irestricted cytotoxic $\mathrm{T}$ lymphocyte epitopes with complex peptide libraries. J Exp Med 181:2097-2108

Udaka K, Wiesmuller KH, Kienle S, Jung G, Walden P (1996) SelfMHC-restricted peptides recognized by an alloreactive $\mathrm{T}$ lymphocyte clone. J Immunol 157:670-678

Wucherpfennig KW, Strominger JL (1995) Molecular mimicry in T cell-mediated autoimmunity: viral peptides activate human $\mathrm{T}$ cell clones specific for myelin basic protein. Cell 80:695-705

Wucherpfennig KW, Hafler DA, Strominger JL (1995) Structure of human T-cell receptors specific for an immunodominant myelin basic protein peptide: positioning of T-cell receptors on HLA-DR2/ peptide complexes. Proc Natl Acad Sci USA 92:8896-8900

Yasunaga S, Kimura A, Hamaguchi K, Ronningen KS, Sasazuki T (1996) Different contribution of HLA-DR and -DQ genes in susceptibility and resistance to insulin-dependent diabetes mellitus (IDDM). Tissue Antigens 47:37-48 